\title{
DEVELOPMENTAL PSYCHOLOGY AND THE SELF
}

\author{
John M. Broughton \\ Department of Psychology \\ Wayne State University \\ Detroit, Michigan 48202 \\ Klaus F. Riegel \\ Department of Psychology \\ University of Michigan \\ Ann Arbor, Michigan 48104
}

To dress correctly for the Bicentennial, psychologists are required to sport the tasteful color combination of pride and optimism. The arrival of the "Self" would rudely shatter the atmosphere, for this unwelcome guest wears a tattered and outre costume. She used to be the life and soul of the party; now people whisper behind her back. "She's charming on the surface, but after a while you find there's no substance to her." If two of the early presidents of the A.P.A., Mary Whiton Calkins and James Mark Baldwin, proclaimed psychology as "the science of selves," so much the worse for the A.P.A.

Like its political past, America's developmental interpretations of the Self are founded upon distinctly different intellectual traditions originating in seventeenth and eighteenth century Europe. The British empiricism of Locke and Hume, which was most significant for experimental psychology and the study of individual differences, also exerted a formative influence upon the psychology of the Self as expressed by American functionalists, most notably Allport. In this tradition, the Self was conceived as arising from experience through a clustering of impressions.

The idea of such an empirical Self constituted an intellectual reaction to the rational Self of Descartes. The Self seen from this latter perspective represents the core that makes any knowledge of the person possible at all; the concrete experiences appear as mere symptoms documenting and demonstrating what is known to begin with. The autonomous Self, although in a more moderate form, entered into the logical a-priorism of Kant, and through Kant influenced American developmental interpretations.

Both orientations, British empiricism and Continental rationalism, remained individual-centered (or rather, "Self-centered"). The social determinants were treated as only secondary. Moreover, both orientations were a-developmental and a-historical. Thus, viewing the Self in its intimate interdependence with social conditions appears to be one of the most original contributions of American sociologists, most conspicuously, the symbolic interactionists. This idea also had its predecessors: proponents of idealistic and materialistic dialecticism like Hegel, Marx, and Engels. Departing from these philosophical orientations, however, symbolic interactionism stripped the dialectics of its concrete historical basis, thus making its interpretation more congruent with the synchronic viewpoints of traditional philosophy and sciences, most notably with the theories of Self originating from British empiricism and Continental rationalism. It remains an important and uncompleted task to elucidate the historical and developmental aspects of the study of Self. 
Instead of the more usual focus on Freudian and neo-Freudian concepts of the Ego which has been well handled by Loevinger, Rapaport, and others, ${ }^{1}$ we will explore the evolution of some other conceptions of Self: the more distinctly American approaches of functionalism, symbolic interactionism, and cognitivedevelopmentalism. First, we will discuss skep tical empiricist critiques of theidea that there is a substantial "Soul." The view that the Self is no more than a SelfConcept is examined to see if it results in a substantially different interpretation. Other reflexive views, which introduce into the Self its extrinsic social relations, are then dealt with, comparing the different approaches of Laing, Goffman, and the Baldwin/Mead tandem. Baldwin's work is the fulcrum upon which we find balanced the symbolic interactionist tradition on the one hand, and the cognitivedevelopmental tradition on the other. The post-Kantian concerns of developmental theories (Baldwin, Piaget, and Kohlberg) then raise the issues of subject/ object relation, intersubjectivity and self-consciousness in all their complexity. However, these theories leave us the "prisoners of form," 2 still without the needed understanding of practical and historical aspects of the Self. Finally, the "double interaction" paradigm of Rubinstein is discussed, as a potential contribution to such an understanding. Throughout, we will be reminded that concepts of Self dialectically condition and are conditioned by concepts of experience, consciousness, and knowledge. ${ }^{3}$

\section{SUBSTANCE AND ANTISUBSTANCE}

Behaviorists like Skinner have rejected the "Self" of everyday language because this concept is imbedded in an approach that

... is a vestige of animism, a doctrine which in its crudest form held that the body was moved by one or more ind welling spirits. 4

To criticize such a crude "thingification" of the Self is, of course, correct. Although in everyday metaphorical parlance we often speak as though we have an "inner man," such a homuncular conception begs the question: What is the Self of the little man? This leads to an infinite regress.

However, that notion of the Self is somewhat of a straw man. In addressing the homunculus notion, one runs the risk of confusing a Medieval or Enlightenment spirtualism with a pre-Socratic animism, and thereby choosing the wrong opponent (after the fashion of Muhammad Ali).

Furthermore, such a criticism does not even serve the purpose of distinguishing behaviorists from humanists. Humanistic psychologists (like Bugental and Allport, for example), also vilify any crass reification of the organism's activity, and find it in the interests of scientific humanism to dispense with the Self or Ego as such. ${ }^{5}$ In this case, therefore, Skinner's ignoratio elenchii serves incidentally to bind him to the Humanists, rather than separate him from them. For both, activity preserves the integrity of the organism, and it is this observable organism that is active, not some introspected Agent, or homunculus.

Others $^{6}$ have disposed of the Self by simply arguing that emphasis on the individual ignores the essentially social and interactive nature of man. The creed of this point of view is that nothing is separated and isolated; every thing is given in relation. This position is often supported by appeal to the situational variability of human behavior, and a downplaying of theories that reify substantial "traits."

These objections, however, leave the Cartesian concept of Self as Substance less impaired than might be imagined. The substantial Soul of Descartes is 
conceived as an immaterial thinking thing, and is not a minature person or a collection of traits. Neither is it a material object, although admittedly Substance is conceived metaphorically on the model of material reality, and as though it occupied a location internal to the person. The substantial Self is the lawlike essence or "nature" of the individual, which is independent, immutable, indivisible, and self-intuiting. Like an explanatory "law of the person," it binds together at a deeper level all the variable particular instances or relations of the manifest person. This allows us to say that these are variations of something, or relations of something to its social context, rather than instances of different things.

The essential attribute of this thing was thought. However, Hume's critique, like William James' after him, intelligently questioned whether one needed to assume that thought was an attribute of something. From his standpoint, the Self was never given to us as a whole. Certainty at tached instead to the individual data of sense experience, ${ }^{8}$ and the soul was merely an illusory belief, or an idle metaphysical speculation. Or in the spirit of James, ${ }^{9}$ if thinking is the essential thing, why not just confine the Self to the present, passing Thought? To paraphrase that scholarly denizen of the Big Apple, Woody Allen, to attempt an empirical study of the Soul is like trying to get a plumber on weekends.

Hume's empiricist interpretation, and James' elaboration of its psychological component, made Self an empirical "me," placing it entirely within experience, and opening the way to a psychological approach to self-conception. This selfconception is not Descartes' inner intuition of the certainty of Self, but is a Self-Concept-a cognitive induction from the regular features of self-experience. In the empiricist view, this induced concept is an abstraction, and as such does not claim to point to anything "real" beyond itself.

A modern example of this approach is the work of Bugental and Zelen in $1950 .{ }^{10}$ They studied individuals' self-concepts simply by asking them to give answers to the question "Who Are You?" Under this kind of interpretation, and using this now-popular ${ }^{11}$ kind of method, the developmental psychologist usually charts the quantitative age-related regularities in such self-descriptions, not claiming to distinguish development from change, ${ }^{12}$ and usually preferring a description of ontogenesis rather than an explanation. This description can deal with changes in the content and organization of the self-concept, with its increasing complexity or efficiency, for example, but does not look for developments in the form of the Self-Concept. All people at all times have a self-concept of basically the same kind.

The functionalist perspective on Self receives its clearest formulation in the work of Gordon Allport ${ }^{5}$ carried out (perhaps not entirely by coincidence) in William James Hall at Harvard. Allport's "Proprium" is an empirical self, comprising the unique attitudes, values, and self-perceptions which are of persistent importance to the individual. At its center is a dynamic "self-image" of the individual's "present abilities, status and roles: and what he would like to become, his aspirations for himself" ${ }^{14}$ (p. 47). The difference between actual present self and future ego-ideal generates a "propriate striving" of the individual, a specific kind of competence motivation which Allport compares to the "selfactualisation" of Goldstein and Maslow. The process of striving by the organism is supposed to maintain the integrity of its boundaries and the internal consistency of the individual's "personality."

The integration of past, present, and future plays a significant role, because the fact that our concerns extend into the future, and (as Hume admitted) (Frondizi, ${ }^{8}$ p. $121 \mathrm{ff}$.), the fact that we can extend our personal identity back- 
wards beyond our memory, are both indicative of some persistent Self over and above a bundle of perceptions. A similar function is served covertly by the emphasis on life crises and struggling.

But does this persistence over time not embarrass the Self-Concept or SelfImage theorist, who appears, in the true spirit of positivism, to want to follow Hume's or James' critique of metaphysical Substance? Ironically, the SelfConcept has taken on many of the characteristics of substantiality that had suffered under the cutting edge of Hume's skepticism and James' pragmatism. The Self-Concept or Proprium is typically attributed stability and permanence, is resistant to change, expresses the "essence" which the person strives to realize, and takes on a central dynamic role, like an Agent, in the individual's life. Although Allport denies it (Evans, ${ }^{13}$ p. 42 ), the idea of Self-Concept even appears to presuppose Cartesian self-knowledge as privileged access to private mental events, expressing the absolute independence central to the concept of Self as Substance. Finally, in this tradition, self-conception is construed as $a$ selfconcept, or a proprium, suggesting a unitary entity. Hume was always embarrassed by the fact that his view indicated the Self was a bundle of perceptions (Frondizi, ${ }^{8}$ p. $121 \mathrm{fn}$.), and not just perceptions per se.

Recently, American humanistic psychologists like Bugental, ${ }^{5}$ and Bohart $^{6}$ have seen the apparent fixity of the Self-Concept as a problem for the man-inthe-street, for the individual self-conceivers, who simply make a mistake in thinking that way instead of in terms of a process or a flux of particulars. If this were the case, we might legitimately ask, as Hume did, for a psychological account of how people come to such an illusory belief. ${ }^{14}$ But is it not also a problem for the theory, encumbered by a confused theoretical construct which, while ushering one metaphysical mistress out of the front door (for reasons of purity) allows another to illicitly sneak in the back? This Marx Brothers routine reflects genuine conceptual problems inherent in the concept of the Self-Concept, such as the following.

1) How does one know which of one's characteristics are unique? Does this not imply knowledge of other selves, also?

2) Even given this, how does one know that these characteristics are properties of the same self, rather than, say, a "fruit salad" from several people?

3) Even given that these are properties of the same self, how do I know that it is $m y$ self, and that these properties pertain exclusively to $m e$ ? (One interesting alternative would be that this "thing" is a "selves-concept," representing general characteristics of the human self, pertaining to all individuals. This would take advantage of the broader meaning of "concept." The empiricist view limits "conceiving" to a quasivisual process of concrete perception. ${ }^{15}$

4) Does the Self-Concept not imply a self-conceiver or a Self conceived? (The hyphen always splits the Self into two parts. Thus, in the ideology of SelfControl, ${ }^{4}$ there must be a "Master-Self" and a "Slave-Self.")

5) If the Self-Concept does not imply a Self, is the Self-concept true of anything, or is it just a set of "attributions" or guesses?

6) If the typifications of oneself are at all veridical, how is it that one can take an objective stance towards oneself? (This again would appear to assume that reflection is reducible to a visual "self-seeing" that is purely receptive and does not transform the Self observed in any way.)

7) Why should we assume that impressions or self-perceptions are absolute givens, when we deny this privilege to the substantial self? 
8) How can we claim that a self-concept or proprium is an empirically discovered clustering of properties, when the self-report techniques used to tap Self-Concept assume that there must be such a constellation of attitudes, for example, in the very question "Who Are You?" It is hard to see what form an empirical disconfirmation of the existence of a Self-Concept or Proprium would take. Allport's Jamesian criterion, that some values and self-perceptions are "warm"13 (p. 42), or more important to the individual than others, seems weak and debatable as evidence. Similarly, the holistic notion of the integrity of the organism, which is basic to the functionalist approach, appears less of a product of factual observation than a precept necessitated by the assumption that experience is essentially fragmentary.

\section{THE INTERSUBJECTIVE SELF}

Hidden behind these issues is a deeper assumption. The theories of the empirical self we have been discussing concern the individual's description of what he or she is. This, ho wever, assumes that the individual already knows somehow that he or she is. Descartes and Kant have in common this rationalist concern with the logically prior self-experience that tells me that I exist. R.D. Laing ${ }^{16}$ therefore took everyone by surprise when he suggested that not only do people not take this for granted, but that it is the ontological question of the Self's existence that underlies personality development and pathology. This would have been no more than an interesting curiosity, again confirming the eccentricity of the British, if it were not for the following fact. Laing argued that the assertion of the Self's existence, which had previously been confined to the shady and speculative realms of metaphysics, was now found to be very relevant indeed in the emergence of personality. In addition, Laing's empirical documentation of behavior, albeit clinical, was enough to pique the interest of even the diehard positivist. Evidence of human self-consciousness was thereby shown to be independent of introspection, a position argued theoretically by Kant long before, in opposition to Descartes. Yet, Laing appeared to take sides with the sceptics, being as virulent an opponent as they of the substantial interpretation of the Subject. He thus backed Hume's critique, while avoiding the narrowness of Hume's view that Existence implied Essence.

Because of this peculiar combination of stances, it has been tempting to regard Laing as a theoretical chameleon, and to assimilate those parts of the mixture that resonated with traditions outside European existentialism and phenomenology. The symbolic interactionism of Mead, Baldwin, and Cooley, developed in the first third of this century, fills such a role neatly, since, like the Laingian view, it stresses interpersonal relations as the matrix from which the Self develops. ${ }^{17}$

Although symbolic interactionism is of ten considered an alternative paradigm to functionalism in the social sciences, it has much in common with Dewey's original emphasis on the situational context. ${ }^{18}$ Self is not a simple biological individual or an essence, but is part of a dialectically elaborated social polarity. Self and Other develop pari passu, through a process of interpersonal interaction at the symbolic or ideational level. One reacts to the other as someone similar to oneself, takes the role of the other, and is thus able to respond covertly to oneself as an object. One has a "generalized self"-the imaginations that others have of the self which are introjected. Similarly, the other is a function of the ideas that the self has of the other. ${ }^{19}$ The development of the self therefore follows the development of role-taking, which, in turn, is dependent on the give-and-take of social experience. Communication is made the point of interpenetration of 
individual and society, and it takes place either through a shared language (Mead) or through acts of social imitation (Baldwin).

This view has in common with the Self-Concept approach that it places the Self within consciousness-as a reflexive self-concept or interpretation. The SelfConcept tradition has in common with other approaches its attempt to render a "nonegological" conception of consciousness (to borrow a phrase from Gurwitsch. ${ }^{20}$ ) The entity "Self" is reduced to a reflexive relation, to a hyphen, as in Self-Concept, Self-Realization, Self-Regulation, Self-Control, and so on. Symbolic interactionism also reduces substance to relation, although it differs in that the relation of self to itself is now through another self. The experience of oneself is dependent upon experiencing the world as containing other selves. The concepts of self and of other selves develop together. This reflective consciousness peculiar to humans is intersubjective, and involves the taking of another's role; it is no longer the activity of an individual alone.

This approach therefore has the advantage of exposing the fictitious quality of an absolutely subjective and private personal experience and the spatialization of Self that occurs when one views it as "inner" rather than "outer." Cooperative expressions of reflection, like science, become understandable. We are, however, left with some familiar problems and some new ones. ${ }^{21}$

1) How do we reintroduce the subject/object relation into this approach which so much emphasizes the subject/subject relation? Whereas the Cartesian model led to a privately subjective and idealistic notion of experience, symbolic interactionism appears to lead to a publicly subjective and idealistic interpretation. Social reality, and even nonsocial reality, are not distinguished from social consciousness. The possibility of "false consciousness" is thereby eliminated, and objectivity becomes absorbed in intersubjectivity (Lichtman ${ }^{21}$ ).

2) Similarly, on the subject side, we again have the problem of distinguishing the Self from a personification of the Self, for as Harry Stack Sullivan says,

... the relation of personifications to that which is personified is always complex and sometimes multiple; and that personifications are not adequate descriptions of that which is personified. ${ }^{7}$ (p. 167)

In the symbolic interactionist's view, is the individual's personification veridical? Does it represent a perception of the self, or is it a mere attribution of characteristics to the self, of dubious and inestimable objectivity?

3) Again, restricting the Self to a perceived or imagined "me" means that the Self is treated as "an object which is in most respects like all other objects." 22 This raises the possibility of taking the role of objects, and makes the Self hard to differentiate from nonconscious and nonself-conscious things. The subjectivity of the Self is thus removed.

4) Why is intersubjectivity necessary for reflection? Is self-consciousness not possible without role-taking? The "outer" now appears to receive undue stress at the expense of the "inner," in reaction against the old "inner" substantial Self. Reflection as role-taking is simply substituted for, and not integrated with, individual self-reflection.

5) This raises the question of how someone knows when he or she is conscious of himself or herself, and when conscious of another self? Said slightly differently, how do I know when I am reflecting on my thoughts, and when on your thoughts or our thoughts, or even someone else's thoughts? 
6) As Dewey has pointed out, ${ }^{23}$ the upshot of this is that making Self a shared meaning, without sufficient attention to the differentiation of Self and Other, leaves the Self to be absorbed into the larger whole of a Social Self. We cannot then account for the psychic sense of individuality. Dewey further argues that symbolic interactionism does not demonstrate the origins of individual and society, only their reciprocal relations to each other, taking their existence for granted to start with. Self is therefore fragmented in a similar way to the empiricist fragmentation mentioned above, the discrete units now being roles indeterminate as to the subjects filling them or taking them.

The apparent consequences just outlined bear a marked resemblance to the loss of Self in other sociological accounts, especially those that emphasize the liberal virtue of "flexibility." For example, Parsons et al. ${ }^{24}$ reduce personality to an anonymous role cluster, at the center of which is no one. Such a role cluster can vary in its complexity and in the degree and efficiency of its organization. ${ }^{15}$ Goffman also uses the concept of "role" in his reduction of Self to its extrinsic relational properties. ${ }^{25}$ The Self for Goffman is no more than a series of "presentations" or false facades, approximating the "false" or "disembodied" Self of Laing. Whereas Laing argues that this division of the "me" from the "I" is a pathology of the Self, for Goffman there is no distinction between this inauthentic, alienated Self and a normal or real Self. ${ }^{26}$

Goffman's "masks" are presented in a semideliberate fashion, in order that the reaction of the other can be predicted and controlled. The Self is thus defined as free agent by its ability to act on the other to act on the Self. ${ }^{27}$ Thus the Selfas-Role corresponds to the Self-as-Idea (Self-Concept), in the sense that the former is something one chooses rather than being the chooser, while the latter is something one thinks, rather than being the thinker.

\section{SELF AS DEVELOPMENT}

Despite the similarities between this approach and symbolic interactionism, the latter differs in that one takes the role of the "generalized other," a universal subjective point of view, rather than (in the dramaturgical metaphor) playing a specific role or part. Prediction or control of the specific content of the concrete other's reactions is not the main purpose in such role-taking.

A certain idealism is suggested by this concentration on the general form of the role, rather than its content, and on the theoretical intent or meaning of thought rather than on the practical intent of action or manipulation. It is not surprising, then, that symbolic interactionism finds its roots largely in Hegel's dialectic of reason, or that it receives its most trenchant criticisms at the hands of neo-Marxist thinkers. ${ }^{28}$ The mutual role-taking described is Hegelian in the sense that it not only comprises a synchronic social dialectic, but also, by the contradictions that it raises, opens up the possibility of a diachronic perspective as well. The Self can not only change content over time, or become more efficiently organized, but can rise to a qualitatively superior level through the radical reconstruction of its underlying assumptions-through a development in form. It becomes more certain of its existence as it becomes progressively differentiated from the Other.

Unlike Goffman, Mead and Baldwin see social knowledge as a developmental process of this kind, although their emphasis is on the diachronic as development more than as history. Modern developmental theorists like Werner, Piaget, and particularly Kohlberg are the contemporary heirs of this tradition. ${ }^{29}$ Such 
theorists follow Hegel's assumption that the real is rational consciousness, and that development is the development of thought. Development is in fact taken as the defining quality of life and of the human Self. It is not simply contingent, therefore, that in Werner, Piaget, and Kohlberg, "Development" and the "Self" find themselves together. It is logically inherent in the organismic model that the Self is that which undergoes organic differentiation and reintegration through successive transformations or "sublations," the differentiations representing decreased egocentrism and increased self-knowledge (Blasi, ${ }^{21}$ ). As MacMurray ${ }^{17}$ points out, "The answer to Hume's scepticism about the form of the material was the construction of the form of the organic." (p. 82)

Both Self and Development then are species-defining properties, a consequence of the fusion of Hegelian with Darwinian thought that the work of Mead, Baldwin, and Dewey represents. ${ }^{30}$ Evolutionary theory emphasized the biological aspect of neo-Hegelian concepts, shifting the center of gravity away from culturalhistorical world views toward the adaptive cognitive development of the biological individual, despite the fact that evolution occurs primarily at the population genetic level. The cognitive-developmental theories have thus strongly resisted the reduction of Self to its extrinsic relations, aligning themselves very much with Kierkegaard, who

... argued that the most important dialectical process is manifested in the subjective, personal development of individual existence. Kierkegaard denied that there are dialectical processes in history or nature, but held that such processes are dominant in the life-histories of individuals. ${ }^{31}$

The invariant logical sequence of stages in cognitive-developmental theories removes one possible source of relativism. However, subordinating the dialectics of history, nature, or social context does not necessarily preserve the Self as entity. Self-as-Organism is a precarious identity-in-difference. Self and Development are in constant tension, since the Self is viewed as existing only in its own self-negation-in its Becoming rather than its Being.

A somewhat illusory impression of stability is afforded by the assumption that there is a "final stage." This is the telos of the Self fully differentiated from the Other, but in the sense of a universal transcendent, or self-conscious Self, aware of its own subjectivity, not a particular individual with unique concrete personality content. ${ }^{32}$ While the idea of a telos does not imply vitalism, it effectively defines the way in which we understand the course of development that culminates in the "logic" of the final stage. However, as Piaget in particular admits $^{32}$ (p. 33f), Godel's theorem demonstrates that there is no way that the logic of any system can substantiate that there is no logic more comprehensive than its own. ... "Final" stages must therefore always stand as provisional. There is always the possibility that a further development might reflexively bring into question even the concept of "stage" itself. ${ }^{23}$ There are already murmurings about the self-transcendence of Piaget's final stage, particualrly with respect to the limitations of a formal logic as the ultimate definition of intelligence. Similarly, Kohlberg metaphorically refers to a mystical-religious "stage 7" modeled after Baldwin and Spinoza, that surpasses his "final" 6th stage of principled moral judgment. Habermas, on the other hand, has made specific theoretical proposals for a seventh stage that lies still within the realm of normative ethics and metaethics. ${ }^{34}$

Keeping in mind, then, the provisional nature of Piaget and Kohlberg's "final" stages, we can still ask how they characterize the mature and fullydifferentiated Self. Without going into the details of their theories, we can 
TABLE 1

PIAGET'S ERAS AND STAGES OF LOGICAL AND COGNITIVE DEVELOPMENT*

Era I (age 0-2) The Era of Sensorimotor Intelligence

Stage 1. Reflex action.

Stage 2. Coordination of reflexes and sensorimotor repetition (primary circular reaction).

Stage 3. Activities to make interesting events in the environment reappear (secondary circular reaction).

Stage 4. Means/ends behavior and search for absent objects.

Stage 5. Experimental search for new means (tertiary circular reaction).

Stage 6. Use of imagery in insightful invention of new means and in recall of absent objects and events.

Era II (age 2-5) Symbolic, Intuitive, or Prelogical Thought

Inference is carried on through images and symbols which do not maintain logical relations or invariances with one another. "Magical thinking" in the sense of (1) confusion of apparent or imagined events with real events and objects and (2) confusion of perceptual appearances of qualitative and quantitative change with actual change.

\section{Era III lage 6-10) Concrete Operational Thought}

Inferences carried on through system of classes, relations, and quantities maintaining logically invariant properties and which refer to concrete objects. These include such logical processes as (1) inclusion of lower-order classes in higher-order classes; (2) transitive seriation (recognition that if $a>b$ and $b>c$, then $a>c) ;(3)$ logical addition and multiplication of classes and quantities; (4) conservation of number, class membership, length, and mass under apparent change.

Substage 1. Formation of stable categorical classes.

Substage 2. Formation of quantitative and numerical relations of invariance.

Era IV (age 11 to adulthood) Formal-Operational Thought

Inferences through logical operations upon propositions or "operations upon operations." Reasoning about reasoning. Construction of systems of all possible relations or implications. Hypothetico-deductive isolation of variables and testing of hypotheses.

Substage 1. Formation of the inverse of the reciprocal. Capacity to form negative classes (for example, the class of all not-crows) and to see relations as simultaneously reciprocal (for example, to understand that liquid in a U-shaped tube holds an equal level because of counterbalanced pressures).

Substage 2. Capacity to order triads of propositions or relations (for example, to understand that if Bob is taller than Joe and Joe is shorter than Dick, then Joe is the shortest of the threel.

Substage 3. True formal thought. Construction of all possible combinations of relations, systematic isolation of variables, and deductive hypothesis-testing.

"From Kohlberg \& Gilligan. ${ }^{42}$

summarize by saying that their final stages share a structure of possibilities, generated through reflection, among which determinate choices are made (TABLES $1 \& 2$ ). ${ }^{35}$ For Piaget, the theoretic Self chooses through an act of scientific judgment and empirical method. ${ }^{36}$ For Kohlberg, the moral Self chooses in an act of Will, and through a method of ethics (akin to Kant's categorical imperative). These mature structures are not just the most "complex," or "flexible." To say that would be to borrow again the functionalist or systemtheory notions of the adaptive organization of content. The consequence of using such concepts is a return to a relativistic position, in which what counts is an ability to accommodate to specific situations, and in which what counts as "flexibility" or "complexity" varies with the cultural or historical context. Also, "complexity" and "flexibility" are, by virtue of their very generality, leveling concepts that apply equally to all domains. Their use can therefore obscure the qualitative difference between logic and morality. By contrast, the final stages 
TABLE 2

DEFINITION OF MORAL STAGES *

Preconventional Level

At this level the child is responsive to cultural rules and labels of good and bad, right or wrong, but interprets these labels in terms of either the physical or the hedonistic consequences of action (punishment, reward, exchange of favors), or in terms of the physical power of those who enunicate the rules and labels. The level is divided into the following two stages.

Stage 1: The punishment and obedience orientation. The physical consequences of action determine its goodness or badness, regardless of the human meaning or value of these consequences. Avoidance of punishment and unquestioning deference to power are valued in their own right, not in terms of respect for an underlying moral order supported by punishment and au thority (the latter being stage 4 ).

Stage 2: The instrumental relativist orientation. Right action consists of that which instrumentally satisfies one's own needs and occasionally the needs of others. Human relations are viewed in terms like those of the market place. Elements of fairness, of reciprocity, and of equal sharing are present, but they are always interpreted in a physical pragmatic way. Reciprocity is a matter of "you scratch my back and I'll scratch yours," not of loyalty, gratitude, or justice.

\section{Conventional level}

At this level, maintaining the expectations of the individual's family, group, or nation is perceived as valuable in its own right, regardless of immediate and obvious consequences. The attitude is not only one of conformity to personal expectations and social order, but of loyalty to it, of actively maintaining, supporting, and justifying the order, and of identifying with the persons or group involved in it. At this level, there are the following two stages:

Stage 3: The interpersonal concordance or "good boy-nice girl" orientation. Good behavior is that which pleases or helps others and is approved by them. There is much conformity to stereotypical images of what is majority or "natural" behavior. Behavior is frequently judged by intention-"he means well" becomes important for the fist time. One earns approval by being "nice."

Stage 4: The "law and order" orientation" There is orientation toward authority, fixed rules, and the maintenance of the social order. Right behavior consists of doing one's duty, showing respect for authority, and maintaining the given social order for it's own sake.

\section{Postconventional, autonomous, or principled level}

At this level, there is a clear effort to define moral values and principles which have validity and application apart from the authority of the groups or persons holding these principles, and apart from the individual's own identification with these groups. This level again has two stages:

Stage 5: The socia/-contract legalistic orientation, generally with utilitarian overtones. Right action tends to be defined in terms of general individual rights, and standards that have been critically examined and agreed upon by the whole society. There is a clear awareness of the relativism of personal values and opinions and a corresponding emphasis upon procedural rules for reaching consensus. Aside from what is constitutionally and democratically agreed upon, the right is a matter of personal "values" and "opinion." The result is an emphasis upon the "legal point of view," but with an emphasis upon the possibility of changing law in terms of rational considerations of social utility (rather than freezing it in terms of stage 4 "law and order"). Outside the legal realm, free agreement and contract is the binding element of obligation. This is the "official" morality of the American government and constitution.

Stage 6: The universal ethical principle orientation. Right is defined by the decision of conscience in accord with self-chosen ethical principles appealing to logical comprehensiveness, universality, and consistency. These principles are abstract and ethical (the Golden Rule, the categorical imperative); they are not concrete moral rules like the Ten Commandments. At heart, these are universal principles of justice, of the reciprocity and equality of human rights, and of respect for the dignity of human beings as individual persons.

*From Kohlberg. ${ }^{54}$ 
of Piaget's and Kohlberg's schemes represent respectively the most logical and the most moral cognitive structures. That is, formal operations generate universally true judgments of logic and scientific reasoning, while stage 6 generates moral judgments of universal ethical validity. ${ }^{37}$ It is logical necessity within formal operational structures, and the prescriptivity of principled moral judgments that make the judgments fit for all, and so represent the universality of the human Self. ${ }^{38}$

Something else that these final stages share, then, is their explicit claim to unify experience in a self-consistent structure of logical or moral judgement. Cognitive logic and morality are therefore different forms of rationality which are sources of consistency making the person a person-any unification of experience must carry with it a corresponding unity of self.

Each affords a "unity of apperception" in Kant's terms, which means that ideas are known as thought by me. Self-consciousness is therefore implicit in the structural consistency of cognition. The unity is not reified, and the whole is no more real than the parts. The final stage is no more real than the special cases of it which comprise the lower stages. So Platonism is avoided.

The Self in this Kantian paradigm is not substantial, but formal. It is a judging attitude, or Self-as-Perspective. It corresponds to a postcritical conception of knowledge in which it is realized that the forms of experience cannot be derived from the experienced objects, but involve $a$ priori constructions of the subject. ${ }^{39}$

\section{RESIDUAL PROBLEMS}

With respect to conceptions of self, we are now left with at least four major questions. First, Kohlberg's "stage 6" does not define a concrete Self-as-Agent, even though morality involves practical interests. It is still an intellectual Self rather than an acting one-it is the transcendent Subject of ideas about practice, a generator of possible actions among which choices can be made. Its practical qualities stop short at the point of putting its choices into effect. Its domain is still the reflective or contemplative one of reasoning and justification, which are necessary but not sufficient conditions for concrete moral decisions. ${ }^{40}$ This moral Self is therefore akin to Piaget's operational Subject. One question left is: how do we integrate these two theoretical, thinking Selves so that we have a single Subject instead of a double one ? $^{44}$ Kohlberg, in Kantian fashion, has suggested a hierarchical relationship in which logical development is necessary but not sufficient for moral development (TABLE 3 ). The hypothesis leads to different empirical predictions from those generated by the "complexity" hypothesis, as well as being logically incompatible with it. It also appears to differ from Piaget's recent ${ }^{43}$ statement, according to which social ideals are derivative of formal operational thought.

Second, even if we could answer the first question, how would we reconcile a single theoretical Self-as-Subject with the Self-as-Agent, the Self with practical intentions which acts concretely to alter the world? Kant's indication, followed specifically by MacMurray on a philosophical level, and by Kohlberg on the levels of theoretical and empirical psychology, is that the theoretical is necessary but not sufficient for the practical. This logically follows from Piaget's argument that in ontogenesis, logos derives from praxis by successive "reflective abstractions." 44 The latter "de-centrate" the individual by selecting out those aspects of its own, practical or sensorimotor experience which are legitimately general to all others (i.e., "universalisable,") thus constructing the norms of objective 
TABLE 3

RELATIONS BETWEEN PIAGET LOGICAL STAGES AND KOHLBERG MORAL STAGES*

\begin{tabular}{lc}
\hline \multicolumn{1}{c}{ Logical Stage } & Moral Stage \\
\hline Symbolic, intuitive thought & Stage 0: The good is what I want and like. \\
Concrete operations, Substage 1 & Stage 1: Punishment-obedience orienta- \\
Categorical classification & tion \\
Concrete operations, Substage 2 & Stage 2: Instrumental hedonism and \\
Reversible concre te thought & concrete reciprocity. \\
Formal operations, Substage 1 & Stage 3: Orientation to interpersonal \\
Relations involving the inverse of & relations of mutuality. \\
the reciprocal & Stage 4: Maintenance of social order, \\
Formal operations, Substage 2 & fixed rules, and authority. \\
Formal operations, Substage 3 & Stage 5A: Social contract, utilitarian \\
& low-making perspective. \\
& Stage 5B: Higher law and conscience \\
orientation. & Stage 6: Universal ethical principle \\
orientation.
\end{tabular}

"All relations are that attainment of the logical stages is necessary, but not sufficient, for attainment of the moral stage. From Kohlberg and Gilligan. ${ }^{42}$

thought. The difficulty here (which Baldwin called one of the "embarrassments of thought") is that de-centration appears to require that objectivity be attained at the expense of concrete subjectivity. This has led Turner to suggest that Piaget's abstract epistemic Subject, which is merely the structuring mechanisms "of the average subject" (Piaget, ${ }^{32}$ p. 69), should be allowed a dialectical "recentration" which returns the definition of selfhood to the individual conscious psyche. Otherwise, the Self threatens to be "truncated" or reduced to a purely objective meaning. ${ }^{45}$ A parallel critique applies to Kohlberg's fully differentiated moral Self, which takes as the end of value a public "Other." 46 The role taken at stage 6 is not the concrete subjective point of view of the individual concerned, but the objective aspects of all singular points of view.

There are thus two issues here, closely intertwined: the relation of form and content, and the relation of judgment and action. If the former is not taken into account, the latter cannot either. Actions based on an objectification of Self and Others cannot entirely escape conformism. Thus, synchronically speaking, Piaget's formal operational subject can become the "prisoner of form" 2 in adhering too strictly to scientific method as the source of decision, rather than his or her own intelligent judgment. By the latter is meant the choice of a concrete subject, a choice that might intelligently employ methods other than that of the physical sciences. Diachronically speaking, we might also remark that forms cannot generate forms, ${ }^{2}$ and so movement from one stage to another, from a lower level of Self-hood to a higher, must involve putting ideas into practice (or more precisely, must not involve inhibiting the action potential of ideas).

A third problem of interest, given that we could reconcile Self-as-Subject and Self-as-Agent, is that we would still be left with the paradox of self-consciousness in the theory. How is the possibility of cognitive-developmental theories to be explained $?^{47}$ The latter pretend to give a genetic account of thought as $a$ whole, and therefore must reflexively include the possibility of themselves, presumably in the Hegelian fashion of postulating their own approach as the 
telos of the development of knowledge. However, even an active Kantian Self is a fixed speculative principle of knowing, or of willing, and seems to lack that very self-developing quality that the theory says gave rise to it. In the postcritical cognitive developmental tradition, we say that we have become aware of the selfformative character of our own consciousness, that as theorists we reflectively understand our selves as subjects, whose subjectivity has developed in correspondence with the progressive elaboration of objective knowledge. If we assume this, then the course of ego development can no longer be said to be fulfilled with the differentiation of a "complete" Kantian transcendental Subject or Free Will, as Piaget and Kohlberg appear to claim it can. Piaget's theory cannot reflexively account for its own existence, or Piaget's own theoretical reflectivity, and we all know that charity must begin at home.

One possibility here is to argue that further levels of reflectivity "beyond formal operations" must be added, in which the Self moves beyond simple selfconsciousness to consciousness of the process of its own self-formation. Here we would need an account of the emergence of a methodological perspectivea developmental epistemology in addition to a developmental logic, or a developmental metaethics in addition to a developmental normative ethics. ${ }^{48}$

These alternatives, however, would still leave us trapped with the "monad" conception of the forms of experience as generating further, more reflective forms within the individual. Developing self-consciousness would now just be the object of consciousness, and vicious circles start to gnash their teeth.

We now move into our fourth and final problem. This is the fact that, like Mannheim's intellectual, ${ }^{49}$ the Self of the Kantian cognitive-developmentalists claims to take an ideal position, above and beyond all perspectives, and free of interest. $^{50}$ Yet if interest is not admitted, fully differentiated structures of reasoning become neutral "methods" or "techniques" that can be used just as effectively in alienation and rationalization as in their opposites. This is reflected in the fact that Piaget does not entertain the active questioning of the assumptions of the scientific method (Broughton, ${ }^{38} \mathrm{pp}$. 29-39). (Kohlberg also appears relatively uncritical of social scientific methodology. ${ }^{46}$ )

It has not been demonstrated that objectivity would be possible without the admission of specific interests. ${ }^{47,49}$ With the reintroduction of interests, imbedded in particular cultural-historical traditions, development can no longer be seen naturalistically as only "adaptation to the environment," or knowledge as only the key to evolutionary self-preservation through "equilibration." Nature and culture are not completely continuous with each other. The inevitable role of action, history, and sociocultural context in the development of knowledge and the Self would therefore appear to require acknowledgment not only within the structure of developmental theories, but equally within the American functionalist and symbolic interactionist traditions.

Cognitive-developmentalists do not deny the presence or impact of the social environment, although its signficance does tend to be relegated to the role of encouraging or holding back "natural" developmental potentials of the individual. Regarding historical factors, the embryological metaphor of "recapitulation," handed down to developmental psychology from Haeckel and von Baer via Hobhouse and G. Stanley Hall, draws attention to the formal parallels between historical change and individual development. This avoids the need to imbed the latter in the former. ${ }^{51}$ It also suggests formal parallels between psychology and biology, without attending to the need to also explicate the relationship of psychic and biological individuality. 


\section{DIALECTICAL PARADIGMS}

All the different interpretations so far reviewed have at least two qualities in common; they place exceptional emphasis upon the individual, and they deemphasize sociocultural contexts and historical changes. For British empiricism it was the sensory impressions of the individual upon which the Self was built, but the process of building it was not elaborated in the form of a systematic developmental interpretation, nor was the changing historical context considered as an influential condition for this development. Rather, the formation of complex ideas, including that of the Self, was analyzed in a principled manner, looking at some of its regularities but without tracing the details of the developmental and historical processes.

For the Continental rationalists, even more so, the Self existed within a developmental and historical vacuum. It was regarded as the prerequisite for knowing and consciousness, neither of which, it was argued, demanded any explanation for their development or their existence in historical context. On the contrary, the Self provided such an explanation and was the only source for it.

Also, the movement represented by symbolic interactionism tended to see the relationships between social conditions and the experiencing Self in a principled or synchronic manner. Undoubtedly, Mead paid some attention to differences in the relationship between the $I$ and the me's under various developmental and historical conditions (as did Locke, Hume, and Kant), but he did not explicitly propose a theory of these changes. This is especially true for the $I$ which appears from nowhere almost in a miraculous fashion. It represents the inner, energizing core of the individual, but it is not developing; it remains unchanged, unpredictable. Unlike the $m e$ 's, who originate and develop through their dynamic interactions between the $I$ and the social conditions, the $I$ is not explained in this or any other manner.

In search of such an answer one might be tempted to lean on Piaget's paradigm of assimilation-accommodation, which in their mutual interaction bring about the operativity and development of the individual, the assimilation by incorporating the object for the sake of the subject, and the accommodation by producing changes in the subject in view of the object. Such a scheme, when extended, could possibly provide an explanation of the inner operations of the organism; that is, of the processes which, in conjunction with those proposed by the symbolic interactionists, would provide a comprehensive interpretation of the Self. Such an extension has not been proposed by Piaget, nor by the students of symbolic interactionism. It is implied, however, in dialectical interpretations proposed in Soviet psychology. In conclusion, we would like to draw your attention to these interpretive attempts.

The first period in the history of Soviet psychology-as described in a most insightful manner by Payne ${ }^{3}$-consisted mainly in the rejection of the former traditions, most of which were imported from continental Europe, in particular, from Germany.

This movement was not primarily concerned with the concept of the Self, but was directed against the introspectionism of early experimental psychology. Inasmuch as such psychology was built upon the classical mind-body dichotomy, the critique by Soviet psychologists was indirectly concerned with the concept of the Self. In this critique, the traditional Western view was rejected as either promoting a purely subjective-mentalistic or an objective-mechanistic interpretation without being able to bridge this gap and provide a comprehensive integration. 
After this early stage of antisubjectivism, antiintrospectionism, and antiidealism, the pendulum swung, indeed, toward mechanistic materialism. This movement therefore represents the other extreme of traditional, Western European thinking and should, from the Soviet point of view, be rejected as strongly as mental or idealistic subjectivism. Eventually, this was done, but in the late twenties mechanistic materialism represented the dominant trend in Soviet psychology and also characterized, for example, the early thinking of Pavlov (or at least the American interpretation of his work).

With the posthumous publication of the "Philosophical Notebooks" by Lenin in $1929,{ }^{52}$ this movement was severely criticized. As a consequence, focused attention was given to cultural and historical determinants of development, that is, to those aspects which play a decisive role in the Marxist's "Classics." Here they appear under the label of "historical dialecticism," as contrasted with "dialectical materialism." Vygotsky ${ }^{53}$ was one of the most outspoken, though not wholeheartedly accepted, proponents of this movement.

With the prevalence of these two successive movements in Soviet psychology, the stage was set for a more embracing integration. This was achieved after the end of World War II and is most convincingly expressed in Rubinstein's double interaction theory.

Rubinstein's synthesis emphasizes the unity of consciousness and behavior. These terms do not denote separate systems; the former is not all internal nor the latter all external; both interpenetrate each other. Consciousness is not a passive contemplative state but an activity; behavior is not merely a movement, but is directed by internal organization. On the one hand, activity objectifies the inner-subjective world; on the other hand, the objective world is reflected in and by the subject. This distinction is very similar to Piaget's comparison of accomodation and assimilation, which produce the successful adaptation of the individual. Rubinstein refers to Marx. "By acting on the external world and changing it, he, at the same time, changes his own nature."

For Rubinstein the study of ontogenesis is not conceivable without the study of phylogenesis. Modifications in either case result in dialectical leaps that are brought about by changes in the structure of the organism. But as these structures change the functions also change, because structure and functions develop as a unit. At the beginning, the development of the organism is determined by the laws of biological evolution. With the phylogenetic emergence of psychic activities, however, development becomes codetermined by the laws of sociohistorical evolution. In particular, man, through his activities and labor, transforms his environment and creates new conditions for individual development. As stated by Payne, ${ }^{3}$ man "creates himself by his own labor by transforming nature to transform himself." (p.90)

When we focus on ontogenesis, the individual's development consists of the acquisition of human culture through his own activities. But this process has to be supplemented by the activities of others, by the activity of society. The activities have to permeate in both directions, from the individual to the culture and from the culture to the individual. The Self and knowledge of the Self are acquired through the individual's activities, but the activities of the society are of equal importance. The Self and knowledge are social in nature.

The dialectical interactions between the individual-psychological and culturalsociological conditions are codetermined by a second system of interactions, that is, those between higher nervous activities and individual-psychological conditions. Rubinstein does not elaborate this interaction at length but refers to the work of Pavlov and his followers. With this renewed emphasis on the inner-biological basis, Rubinstein completes his synthesis. In the words of 
Payne, "The relation of the psychic to the material world is fundamentally twofold: to the inner matter of the brain (this relation constitutes the psychic in the quality of higher nervous activity) and to the outer matter of the external world in which relationship the psychic takes on the quality of ideal and subjective. The first quality Rubinstein calls the ontological aspect of the psychic; the second he calls gnoseological or theory-of-knowledge aspect."3 (p. 98)

The notion of dialectical interactions penetrates all of Rubinstein's interpretations. It is most clearly revealed by the concept of "constitutive relationism," which he adopts from Hegel and Lenin. Lenin" emphasized that: "Every concrete thing, every concrete something, stands in multifarious and of ten contradictory relations to everything else: ergo it is itself and some other." (p. 124) In Payne's formulation, ${ }^{3}$ "... . every phenomenon or thing is determined and constituted by its relation to all the other phenomena of reality" (p. 99); consequently, individual-psychological states have a plurality of structures. There are several intrinsic structures, relating psychic activities to the brain, and several extrinsic structues relating them to the outer correlations both in the sociological and physical sense.

Rubinstein's interpretations lead to a reformulation of the mind-body problem. Traditionally the solution of this problem has been sought by determining the nature of both, the mind and the body, and then by investigating their interdependence. For Rubinstein the solution has to proceed in the reverse order. The relationship determines how we conceive of mind and how we conceive of body. Through the developmental interactions anchored in both inner and outer activities, the Self emerges. Thus, mind and body collapse upon the intersect of these two developmental processes. The Self produces these two interaction processes, and at the same time it is produced by them. Seen from a dialectical perspective-the Self orginates at the interaction of two developmental interaction systems; at the same time, it creates these two interaction systems. In other words, it is itself and some other.

\section{ACKNOWLEDGMENTS}

Thanks are due to the following for their contributions to the ideas discussed here: Augusto Blasi, Howard Gadlin, Emil Oestereicher, Edmund Sullivan, Michael Watts, and Robert Wozniak. Some unpublished notes by Lawrence Kohlberg were also of help. We are most grateful to Linda Lees for her help in preparing the manuscript. It should be noted that Riegel wrote the introduction and the final section on dialectics and Rubinstein, and Broughton contributed the sections on self-concept, symbolic interactionism, and cognitive-development. As Riegel pointed out at the conference (in true dialectical fashion!), the authors are not necessarily in agreement on all the issues discussed.

\section{NOTES AND REFERENCES}

1. RAPAPORT, D. 1959. A historical survey of psychoanalytic ego psychology. Psychological Issues 1: 5-17. LEITES, N. 1971. The New Ego. Science House. New York, N.Y. LOEVINGER, J. 1976. Ego Development. Jossey-Bass. San Francisco, Calif. YANKELOVICH, D. \& W. BARRETT. 1970. Ego and Instinct. Random House. New York, N.Y.

2. OESTEREICHER, E. 1975. Form and praxis: a contribution to the theory of cultural forms. Unpublished. Richmond College, CUNY, New York, N.Y.

3. KURFISS, J. 1976. Developmental origins and psychological implications of "awareness." Paper presented at ann. mtg. Western Psychol Ass. April 8 Los Angeles, Calif. PAYNE, T.R. 1968. S. L. Rubinstein and the Philosophical Foundations of Soviet Psychology. D. Reidel. Dordrecht, The Netherlands. 
4. SKINNER, B.F. 1974. About Behaviorism: 184 ff. Random House. New York, N.Y.

5. ALLPORT, G.W. 1955. Becoming: 36-39. Yale University Press. New Haven, Conn. BUGENTAL, J.F.T. 1971. The self ... process or illusion? In Existential Humanistic Psychology. T.C. Greening, Ed. Brooks-Cole. Belmont, Calif.

6. DUMONT, M.P. 1974. The Frankenstein factor. The Real Paper. June 12: 14. BOHART, A.C. 1976. Self-attribution and humanistic psychology. Paper presented at ann. mtg. of Western Psychol. Ass. April 8. Los Angeles, Calif. For a critical reply to Dumont, see BROUGHTON, J.M. 1974. Between the lines. The Real Paper, June 26: 2 .

7. SUZUKI, D.T. 1960. Lectures on Zen Buddhism. In Zen Buddhism and Psychoanalysis. E. Fromm, D.T. Suzuki, and R. DeMartino, Eds. Harper \& Row. New York, N.Y. BOHART, A.C. See Ref. 6. SULliVAN, N.S. 1953. The Interpersonal Theory of Psychiatry: $300 f$. Norton. New York, N.Y.

8. CASSIRER, E. 1923. Substance and Function: $387 \mathrm{ff}$. Open Court. Chicago, Ill. FRONDIZI, R. 1953. The Nature of the Self. Southern Illinois University Press. Carbondale, Ill.

9. JAMES, W. 1890. The Principles of Psychology. Vol. 1: 291-401. Henry Holt. New York, N.Y. HENRICH, D. 1969. Self-consciousness. Unpublished paper. University of Michigan. Ann Arbor, Mich.

10. BUGENTAL, J.F.T. \& S. L. ZELEN. 1950. Investigation into the self-concept. J. Personality. 18: 483-498.

11. A review of Self-Concept research is presented in WYLIE, R.C. 1961. The Self-Concept. University of Nebraska Press. Lincoln, Nebraska. For a representative selection of work in the Self-Concept tradition, see the following. KUHN, M.H. \& T. S. MCPARTLAND. 1965. An empirical investigation of self attitudes. American Sociol. Rev. 19: 68-76. SCHLIEN, J. 1962. The self-concept in relation to behaviour. Religious Education, 10: Slll-S1 27. KATZ, P. \& E. ZIGLER. 1967. Self-image disparity: a developmental approach. J. Personality and Social Psychol. 5(2): 186-195. GORDON, C. 1968. Self conceptions: configurations of content. In The Self in Social Interaction. C. Gordon \& K.J. Gergen, Eds. John Wiley \& Sons. New York, N.Y. GIL.L, M.P. \& V.R. D'OYLEY. 1968. The construction of an objective measure of self concept. Paper read at the ann. mtg. Amer. Educa. Res. Ass. Chicago, Ill. GERGEN, K.J. 1971. The Concept of Self. Holt, Rinehart and Winston. New York, N.Y.

12. Regarding the distinction between development and change, see BLASI, A. 1976. Concept of development in personality theory. In Ego Development. J. Loevinger. 29-53. Jossey-Bass. San Francisco, Calif.

13. ALLPORT, G.W. See Ref. 5. EVANS, R.I. 1971. Gordon Allport: The Man and His Ideas. E. P. Dutton. New York, N.Y. TARULE, J.M. 1976. The self-reflective capacity in adults. Unpublished qualifying paper, Graduate School of Education, Harvard Univ. Cambridge, Mass.

14. BROUGHTON, J.M. Epistemology as ideology: the cognitive development of subject/ object concepts. In Dialectics as a Paradigm for the Social Sciences. A. Harris, Ed. To be published.

15. MACMURRAY, J. 1957. Self as Agent: 105/6. Faber and Faber, London, England.

16. LAING, R.D. 1960. The Divided Self. Tavistock. London, England.

17. MEAD, G.H. 1934. Mind, Self and Society. University of Chicago Press. Chicago, Ill. BALDWIN, J.M. 1897. Social and Ethical Interpretations. Macmillan. New York, N.Y. COOLEY, C.H. 1902. Human Nature and the Social Order. Charles Scribner's Sons. New York, N.Y. DENZIN, N.K. 1972. The genesis of self in early childhood. The Sociological Quarterly 13:291-314. KOHLBERG, L. 1969. Stage and Sequence. In Handbook of Socialisation Theory and Research. D. Goslin, Ed. Rand McNally. Chicago, Ill. SELMAN, R. 1974. The development of conceptions of interpersonal relations. Mimeoed. Harvard/Judge Baker Social Reasoning Project. Boston, Mass. For Laing's most expressly interactionist position, see LAING, R.D. 1961. Self and Others. Tavistock Publications. London, England; LAING, R.D., H. PHILLIPSON \& A.R. LEE. 1966. Interpersonal Perception. Springer. New York, N.Y. The method of existential dialectics is more fully explicated in ESTERSON, A. 1970. The Leaves of Spring. Tavistock Publications. London, England. Both Laing and Esterson explicitly acknowledge the influence of the Scottish philosopher MacMurray, whose interactionism is perhaps best expounded in MACMURRAY, J. 1961. Persons in Relation. Faber and Faber. London, England.

18. TIBBETTS, P. 1971. John Dewey and contemporary phenomenology on experience and the subject/object relation. Philosophy Today 15(4): $250-275$.

19. Similar concepts arise in psychoanalytic theory. See LEITES, N.' Section 2.

20. GURWITSCH, A. 1966. A non-egological conception of consciousness. In Studies 
in Phenomenology and Psychology. A. Gurwitsch, Ed. Northwestern Univ. Press. Evanston, Ill. For a critique of non-gological theories in general, see HENRICH, D. Ref. 9.

21. LICHTMAN, R. 1970. Symbolic interactionism and social reality: some Marxist queries. Berkeley Journal of Sociology 10: 75-94. BLASI, A. 1975. Role-taking and the development of social cognition. Paper presented at the annual meeting of the American Psychol. Ass. Chicago, Ill. August 28. McN ALL, S. G. \& J.C.M. JOHNSON, 1975. The new conservatives: ethnome thodologists, phenomenologists and symbolic interactionists. The Insurgent Sociologist. 5(4): 49-66.

22. KUHN, M.H. \& T.S. MCPARTLAND. See Ref. 11, p. 112. Regarding the loss of the subjective "I," see MOORE, J.S. 1933. The problem of self. Philosophical Review. 62: 487-499.

23. DEWEY, J. 1890. On some current conceptions of the term 'self'. Mind 15: 58-74. DEWEY, J. 1898. Social and Ethical Interpretations in Mental Development: review of book. Philosophical Rev. 7: 398-409.

24. PARSONS, T. \& E. SHILS, Eds. 1951. Toward a General Theory of Action: 18. Harvard Univ. Press. Cambridge, Mass.

25. GOFFmaN, E. 1969. The Presentation of Self in Everyday Life. Penguin Press. London, England. Goffman's position is currently receiving a shot in the arm from Rom Harre-see HARRE, R. Some remarks on "rule" as a scientific concept. In Understanding Other Persons. T. Mischel, Ed. Blackwell. Oxford, England. For a brilliantly ironic critique of Parsons, Goffman, and others, see HELMER, J. 1970. The face of the man without qualities. Social Res. 37(4): 547-579. For further reflections on "role" see MEILAND, J. 1975. Styles of life: self, identity and roles. Unpublished. Univ. Michigan. Ann Arbor, Mich.

26. While Laing's symbolic interactionism has been assimilated to the Mead tradition, this more critical approach to alienation and ontological insecurity appears to have had little or no effect on developmental psychology, which has typically assumed that we know that we are, and gone on to ask what we are.

27. Compare HEGEL, G.W.F. 1975. Logic: xvii ff. Oxford Univ. Press. Oxford, England. Also SKINNER, B.F. Ref. 4.

28. JACOBY, R. 1975. Social Amnesia. Beacon Press. Boston, Mass. LICHTMAN, R. ${ }^{21}$

29. Baldwin was wont to lunch with Piaget's mentor Claparede in Paris. See KOHLBE RG, L. Forthcoming. Baldwin's theory of moral development. To appear In Baldwin's Theory of Development: A Current Appraisal. D.J. Freeman-Moir, J.M. Broughton, and L. Kohlberg, Eds. Kohlberg's work is heavily indebted to Dewey and Baldwin, as Kohlberg himself states. ${ }^{17}$ Selman 17 (op. cit.) and Loevinger ${ }^{1}$ are also much influenced by Baldwin's work, although less directly.

30. See MOIR, J. 1975. A sense of the general. Unpublished doctoral dissertation. Harvard Univ. Cambridge, Mass.; NOVACK, G. 1975. Pragmatism and Marxism. Pathfinder Press. New York, N.Y. PIAGET, J. 1971. Biology and Knowledge. Univ. Chicago Press. Chicago, Ill.

31. STACK, G.A. 1971. On the notion of dialectics. Philosophy Today 15: 276-291. Related commentary is given in MARSTIN, R. 1974. Structuralism: limits and possibilities. Unpublished paper. Harvard University, Cambridge, Mass.; and RIEGEL, K.F. 1976. From traits and equilibrium toward developmental dialectics. Nebraska Symposium on Motivation. W. J. Arnold and J. K. Cole, Eds. Univ. Nebraska Press. Lincoin, Nebraska.

32. This abstract epistemic subject is characterized in PIAGET, J. 1970. Structuralism. Basic Books. New York, N.Y. Critical commentary appears in CASSEL, T.Z. 1972. A system of structured minds. Contemporary Psychology 17(12): 695-6; and TURNER, T. Piaget's structuralism. American Anthropol. 75: 351-373. See also KEGAN, R. 1976. Self and other: structural affect in ego transformation. Unpublished paper. Harvard Univ. Cambridge, Mass.

33. RIEGEL, K.F. 1973. Dialectical operations: the final period of cognitive development. Human Devel. 16: 346-380; FREEDLE, R. 1976. Logic, general systems and human development: preliminaries to developing a psycho-social linguistics. In Piaget and Beyond, Vol. 7. \& G. Steiner, Ed. Kindler. Zurich, Switzerland.

34. KOHLBERG, L. 1973. Continuities and discontinuities in childhood and adult moral development revisited. In Lifespan Developmental Psychology-Personality and Socialisation. P. Baltes \& W. K. Schair, Eds. Academic Press. New York, N.Y. HABERMAS, J. 1975. Moral development and ego identity. Telos 24: 41-55.

35. KURFISS, J. 1975. Late adolescent development: a structuralepistemological perspective. Unpublished doctoral dissertation. Univ. Washington. Seattle, Wash. See also ERIKSON, E. 1968. Identity: Youth and Crisis. Norton. New York, N.Y.; PERRY, 
W. 1968. Forms of Intellectual and Ethical Development in the College Years. Holt, Rinehart and Winston. New York, N.Y.; LOEVINGER, J. \& R. WESSLER. 1970. Measuring Ego Development. Vol I. Jossey-Bass. San Francisco, Calif. BLASI, A. 1976. Personal responsibility and ego development. In They Need Not Be Pawns: Toward Self-Direction in the Urban Classroom. R. DeCharms, Ed. Irvington Publishers. New York, N.Y. VAN DEN DAELE, L. 1975. Ego development in dialectical perspective. Human Develop. 18: 129-142.

36. BLASI, A. \& E.C. HOEFFEL. 1974. Adolescence and formal operations. Human Develop. 17: 344-363.

37. KOHLBERG, L. 1975. Why stage 6 is best. In Collected Papers. Vol Il. L. Kohlberg. Harvard Graduate School of Education, Cambridge, Mass.

38. BALDWIN, J.M. 1906-11. Thought and Things. Swann Sounenschein. London, England. 1975. Arno Press. New York, N.Y. BROUGHTON, J.M. 1974. The Development of natural epistemology in adolescence and early adulthood: ch. 5 . Unpublished doctoral dissertation. Harvard Univ. Cambridge, Mass.

39. LONERGAN, B.J.F. 1968. The Subject: 22. Marquette Univ. Press. Milwaukee, Wis. MACMURRAY.J. 15

40. BROUGHTON, J.M. The cognitive-developmental model of morality: a reply to Kurtines \& Greif. Submitted for publication.

41. This is the question of the consistency of sources of consistency-i.e., the basic unity of the person which gives form to the logical and the moral (as well as the aesthetic, religious, epistemological, ontological, etc.) This question is that posed by Loevinger ${ }^{1}$ and Blasi $\mathrm{i}^{12}$ as the matter of "ego development." It should be noted that Loevinger also includes aspects of motivation and action in her conception of the Ego, and so offers an alternative to the Kohlberg approach, which first differentiates cognition and action and then asks what the relation is between them.

42. KOHLBERG, L. \& C. GILLIGAN. 1971. The adolescent as philosopher: the discovery of the self in a postconventional world. Daedalus 100(4): 1051-1086.

43. INHELDER, B. \& J. PIAGET. 1958. The Growth of Logical Thinking from Childhood to Adolescence. Basic Books. New York, N.Y. See also BL ASI, A. \& E.C. HOFFEL. ${ }^{6}$

44. WARTOFSKY, M. 1971. From praxis to logos. In Cognitive Development and Genetic Epistemology. T. Mischel, Ed. Academic Press. New York, N.Y. FURTH, H. 1969. Piaget and Knowledge. Prentice-Hall. Englewood Cliffs, N. J.

45. LONERGAN, B.J.F. ${ }^{39}$ BLASI, A. ${ }^{12}$ BALDWIN, J.M. 38 Vol I, p. 269.

46. MORELLI, E.A. 1975. The sixth stage of moral development: a dialectical analysis: 24f. Unpublished. Univ. of Toronto. Toronto, Canada.

47. Cf. HABERMAS, J. 1971. Knowledge and Human Interests: Ch. I. Beacon Press. Boston, Mass. Also, see GADLIN, H. Toward a dialectical psychology: hermeneutic understanding and theoretical self-consciousness. To appear In Dialectics as a Paradigm for the Social Sciences. A. Harris, Ed.

48. BOYD, D. 1976. From conventional to principled morality. Unpublished doctoral dissertation. Harvard Univ. Cambridge, Mass.

49. KOLAKOWSKI, L. 1971. The epistemological significance of the aetiology of knowledge: a gloss on Mannheim. Triquarterly 22: 221-238.

50. KOLAKOWSKI, L. 1975. Very strong doubts about humanism. Paper presented at Univ. Michigan. Ann Arbor, Mich. Oct. 24.

51. TOULMIN, S. 1972. Human Understanding. Princeton University Press. Princeton, N.J.

52. LENIN, V.I. 1929. Philosophical Notebooks. In Collected Works: Vol 38. International Publishers. New York, N.Y.

53. VYGOTSKY, L.S. 1962. Thought and Language. M.I.T. Press. Cambridge, Mass.

54. KOHLBERG, L. 1971. From is to ought: how to commit the naturalistic fallacy and get away with it. In Cognitive Development and Genetic Epistemology. T. Mischel, Ed. Academic Press. New York, N.Y.

55. BUCK-MORSS, S. 1975. Socio-economic bias in Piaget's theory, and its implications for the cross-culture controversy. Human Devel. 18: $35-49$. 